\title{
Keragaan dan Produksi Umbi G2 Kentang Menggunakan Sumber Benih yang Berbeda
}

\author{
Performance and Poduction of G2 Potato Tuber Seeds Using Diference Seed Sources \\ Andi Azhari Putra ${ }^{1}$, Awang Maharijaya ${ }^{2,3 *}$, dan Sobir ${ }^{2.3}$ \\ Diterima 05 Maret 2018/Disetujui 04 Februari 2019
}

\begin{abstract}
Potato (Solanum tuberosum L.) seed production by using tubers and cuttings from two local varieties have been conducted to determine their performance and production in the field. Currently in Indonesia, the use of potato cuttings is limited to the production of GO and G1 tuber seeds in controlled conditions (greenhouse or screenhouse). This research used a factorial Randomized Complete Block Design with varieties (RGHOI and Medians) and seed sources (tubers (GO) and cuttings) as the factor and five replication. The data were analyzed using analysis of variance followed by Duncan's multiple range tests. The result showed that the plants derived from cuttings on both varieties produced more leaves and branches. Otherwise plant height were not significantly different. The production of tubers was not significantly different with 5.2 to 5.9 tubers per plant. Tuber yield of plants derived from tubers on both cultivars was higher than the plants derived from cuttings. However small size tuber $(<40 \mathrm{~g})$ percentage of plants derived from cuttings was higher with $82.0 \%$ (Medians) and $94.1 \%$ (RGHO1) per plant.
\end{abstract}

Keywords: cuttings, potato propagation, seed propagation, Solanum tuberosum L., tuber

\begin{abstract}
ABSTRAK
Produksi benih G2 kentang (Solanum tuberosum L.) menggunakan umbi dan setek dari dua varietas lokal dilakukan untuk mengetahui keragaan dan produksinya di Lapangan. Saat ini di Indonesia, setek kentang digunakan secara terbatas untuk produksi umbi G0 dan G1 pada kondisi terkontrol (rumah kaca atau rumah kasa). Rancangan Kelompok Lengkap Teracak (RKLT) faktorial digunakan pada penelitian ini dengan varietas (RGH01 dan Medians) dan sumber benih (umbi (G0) dan setek) sebagai faktor dan lima ulangan. Data dianalisis dengan sidik ragam yang kemudian dilanjutkan dengan uji Duncan. Tanaman kentang yang ditanam dengan sumber benih setek menghasilkan jumlah daun dan cabang yang lebih banyak pada kedua varietas. Namun, tidak berbeda nyata pada peubah tinggi tanaman. Jumlah umbi per tanaman menunjukkan hasil tidak berbeda nyata pada seluruh kombinasi perlakuan dengan 5.2 hingga 5.9 umbi per tanaman. Produktivitas umbi yang lebih besar dihasilkan oleh tanaman kentang dengan sumber benih umbi pada kedua varietas. Persentase umbi kelas $\mathrm{S}(<40 \mathrm{~g})$ yang lebih besar diperoleh dari tanaman kentang dengan sumber benih setek sebesar $82.0 \%$ (Medians) dan 94.1\% (RGH01).
\end{abstract}

Kata kunci: perbanyakan benih, perbanyakan kentang, setek, Solanum tuberosum L., umbi

\section{PENDAHULUAN}

Kentang (Solanum tuberosum L.) merupakan salah satu komoditas hortikultura penting dan mendapat prioritas untuk dikembangkan. Nilai ekonomi kentang yang tinggi dapat menjadi sumber pendapatan bagi petani dan masyarakat. Kentang merupakan sumber karbohidrat yang memiliki potensi untuk dikembangkan dalam menunjang program diversifikasi pangan. Selain itu, kentang untuk kebutuhan industri mulai

\footnotetext{
${ }^{1}$ Mahasiswa Departemen Agronomi dan Hortikultura, Fakultas Pertanian, Institut Pertanian Bogor

Jl. Meranti, Kampus IPB Darmaga, Bogor 16680

${ }^{2}$ Departemen Agronomi dan Hortikultura, Fakultas Pertanian, Institut Pertanian Bogor

Jl. Meranti, Kampus IPB Darmaga, Bogor 16680

${ }^{3}$ Pusat Kajian Hortikultura Tropika, Institut Pertanian Bogor

Kampus IPB Baranangsiang Jalan Raya Pajajaran Bogor 16144

E-mail : awang.maharijaya@gmail.com (*Penulis korespondensi)
} 
dikembangkan seiring dengan meningkatnya kesejahteraan masyarakat serta gaya hidup (Duriat et al., 2006).

Produksi kentang di Indonesia pada tahun 2015 sebesar 1213038 ton dengan produktivitas 18.23 ton ha $^{-1}$ (Kementan, 2017). Jika dibandingkan dengan potensi hasil kentang varietas Granola Kembang sebesar 38-50 ton ha $^{-1}$ (Kementan, 2006a), produktivitas kentang di Indonesia masih memiliki potensi untuk ditingkatkan. Salah satu penyebab rendahnya produktivitas kentang adalah penggunaan benih kentang bermutu oleh sebagian petani yang masih minim (Direktorat Perbenihan Hortikultura, 2015). Minimnya penggunaan benih bermutu oleh petani dikarenakan ketersediaan benih yang terbatas, kurangnya modal petani dan rendahnya kesadaran petani untuk menggunakan benih kentang bersertifikat. Sumber benih yang digunakan oleh petani antara lain benih produksi sendiri, benih dari petani lain, benih impor dan benih benih dari penangkar (Sayaka dan Hestina, 2011).

Sistem perbenihan kentang bersertifikat di Indonesia sebelumnya diatur melalui Peraturan Menteri No. 40/2006 tentang Pedoman Perbenihan Kentang (Kementan, 2006b). Peraturan tersebut memuat mengenai petunjuk teknis produksi benih kentang (G0G4). Namun menurut Wattimena (2006), satu siklus produksi sampai menghasilkan umbi benih G4 membutuhkan waktu \pm 40 bulan sehingga tidak dapat mengimbangi permintaan dan kebutuhan benih kentang bersertifikat. Selanjutnya pada keputusan Menteri Pertanian Republik Indonesia Nomor: 20/Kpts/SR.130/IV/2014 tentang Perbanyakan dan Sertifikasi Benih Kentang memutuskan persyaratan teknis perbanyakan benih kentang G3 dan G4 tidak berlaku. Saat ini, benih kentang bermutu dimulai dari kelas Benih Penjenis (BS), Benih Dasar (BD/G0), Benih Pokok (BP/G1) dan Benih Sebar (BR/G2) (Direktorat Perbenihan Hortikultura, 2014).

Pola perbanyakan benih kentang bermutu mengikuti pola perbanyakan satu generasi (one generation flow) dengan perbanyakan secara vegetatif menggunakan umbi atau setek sebagai benih. Pola perbanyak ini diawali dengan produksi benih penjenis melalui inisiasi in vitro hingga menghasilkan setek mikro atau umbi mikro. Benih penjenis ditanam untuk menghasilkan benih G0, kemudian benih G0 ditanam untuk menghasilkan benih G1 dan benih G1 ditanam untuk menghasilkan benih G2. Waktu yang diperlukan sejak meristem kentang diinisiasi secara in vitro hingga diperoleh Benih Sebar adalah \pm 24 bulan (Direktorat Perbenihan Hortikultura, 2014). Sistem perbanyakan ini membutuhkan waktu yang masih cukup lama, sedangkan saat ini ketersedian benih bermutu masih terbatas serta permintaan benih dan umbi kentang yang terus meningkat.

Penggunaan setek kentang di Indonesia oleh penangkar umumnya terbatas pada produksi umbi kelas G0 dan kelas G1 dalam kondisi terkontrol seperti pada rumah kaca atau rumah kasa. Produksi umbi G2 kentang menggunakan benih sumber setek dapat dilakukan dalam waktu \pm 16 bulan mulai dari inisasi in vitro hingga dihasilkan umbi G2. Hal ini dikarenakan setek tidak melalui masa dormansi seperti umbi G0 dan G1 sehingga waktu produksi dapat lebih cepat.

Penelitian sebelumnya telah menunjukkan bahwa setek kentang dapat digunakan sebagai sumber benih untuk produksi umbi di lapang (Wattimena dan McCown, 1983; McCown dan Wattimena, 1987; Levy, 1988; Lecrec dan Donnelly, 1990; Särekanno et al., 2010a; 2010b; Lommen, 2015; Wrobel, 2014, 2015; Al Mamum et al., 2016; Hossain et al., 2017). Namun, keragaan dan produksi umbi menggunakan sumber benih setek di lapang menggunakan varietas kentang yang telah dilepas di Indonesia belum dilaporkan. Penelitian ini bertujuan untuk mengetahui pengaruh sumber benih berupa umbi dan setek serta interaksinya dengan varietas terhadap keragaan dan produksi umbi G2 (benih sebar) kentang di lapang.

\section{BAHAN DAN METODE}

Perbanyakan sumber benih dilakukan di Desa Tambakbaya, Kecamatan Cisurupan sedangkan percobaan dilakukan di Desa Margamulya, Kecamatan Cikajang, Kabupaten Garut, Jawa Barat, mulai Februari sampai Juli 2017.

Rancangan percobaan yang digunakan adalah Rancangan Kelompok Lengkap Teracak (RKLT) dua faktor dengan lima ulangan. Faktor pertama ialah varietas yaitu RGH01 dan Medians, sementara faktor kedua ialah sumber 
benih yaitu benih umbi G0 dan setek sehingga terdapat empat kombinasi perlakuan. Setiap kombinasi diulang sebanyak lima kali sehingga terdapat 20 petak percobaan. Petak percobaan merupakan dua buah garitan dengan panjang 5 $\mathrm{m}$ dan jarak antar garitan $0.7 \mathrm{~m}$. Benih ditanam dengan jarak dalam garitan $0.3 \mathrm{~m}$ sehingga setiap satu percobaan terdiri atas 36 tanaman kentang. Setiap petak percobaan diambil 10 tanaman contoh.

Prosedur produksi benih G2 mengikuti Standar Operasional Prosedur (SOP) produksi benih kentang Direktorat Perbenihan Hortikultura (2015) yang disesuaikan dengan kondisi lokasi percobaan agar diperoleh benih bermutu dan sesuai dengan Persyaratan Teknis Minimal (PTM) benih kentang. Prosedur tersebut terdiri atas empat tahapan, yaitu persiapan sumber benih (perbanyakan setek dan pemecahan dormansi umbi G0), penanaman di lapang, pemeliharan dan pemanenan.

Perbanyakan setek dilakukan dengan memotong tunas apikal dari planlet kentang sebanyak satu buku menggunakan silet. Setek selanjutnya ditanam pada pot tray yang berisi media steril dan dipelihara di rumah kasa. Aplikasi IBA dengan dosis $10 \mathrm{ml} \mathrm{L}^{-1}$ dilakukan selama 5 hari setelah tanam atau hingga tanaman mulai berakar kemudian dilanjutkan dengan penyiraman rutin hingga setek berumur 4 minggu dan siap untuk dipindah ke lapang. Umbi G0 disimpan pada ruangan yang memiliki sirkulasi udara yang baik hingga pecah dorman. Pecah dorman ditandai dengan munculnya kecambah pada mata tunas.

Pupuk kandang yang berasal dari kotoran ayam petelur sebanyak 25 ton $\mathrm{ha}^{-1}$ diaplikasikan dua minggu sebelum penanaman. Umbi G0 kelas $\mathrm{S}(<5 \mathrm{~g})$ yang telah pecah dorman ditanam pada kedalaman $10 \mathrm{~cm}-15 \mathrm{~cm}$ kemudian ditutup dengan tanah. Setek berumur 28 hari yang sehat dan seragam berukuran \pm 8 $\mathrm{cm}$ ditanam dengan cara memindahkan (transplanting) dari pot tray ke garitan.

Kegiatan pemeliharaan yang dilakukan meliputi penyiraman, pengendalian gulma, pengajiran, pembumbunan, pemupukan serta pengendalian hama dan penyakit. Pupuk yang diaplikasikan pada 3 minggu setelah tanam (MST) adalah pupuk NPK Mutiara (16:16:16) sebanyak $375 \mathrm{~kg} \mathrm{ha}^{-1}$ serta pupuk $\mathrm{KCl}$ sebanyak $375 \mathrm{~kg} \mathrm{ha}^{-1}$, sedangkan pada 6 MST diaplikasikan pupuk NPK Mutiara (16:16:16) sebanyak $25 \mathrm{~kg} \mathrm{ha}^{-1}$, pupuk ZA sebanyak 160 $\mathrm{kg} \mathrm{ha}^{-1}$ dan TSP sebanyak $160 \mathrm{~kg} \mathrm{ha}^{-1}$. Pengendalian gulam dan pembumbunan dilakukan bersamaan dengan aplikasi pupuk, sedangkan pengajiran dilakukan pada 3 MST. Aplikasi pestisida berupa insektisida dan fungisida dilakukan setiap satu minggu sekali. Pestisida yang digunakan berbahan aktif klorfenapir $100 \mathrm{~g} \mathrm{~L}^{-1}$, abamektin $0.5 \mathrm{ml} \mathrm{L}^{-1}$, propamokrab hidroklorida $3 \mathrm{ml} \mathrm{L}^{-1}$ dan propineb $2 \mathrm{~g} \mathrm{~L}^{-1}$.

Panen dapat dilakukan apabila tanaman sudah mencapai umur panen sesuai dengan varietas atau ditandai dengan layunya tanaman serta kulit umbi sudah kuat dan tidak mengelupas. Umbi dipanen secara manual dengan cara menggali tanah dan mengambil dengan tangan. Umbi yang telah dipanen dibersihkan dari tanah yang menempel dan dikumpulkan dalam wadah.

Peubah pengamatan terdiri atas peubah pertumbuhan vegetatif dan komponen hasil. Peubah pertumbuhan vegetatif yang diamati antara lain tinggi tanaman $(\mathrm{cm})$ diukur dari pangkal batang hingga titik tumbuh tertinggi pada batang utama, jumlah daun dihitung daun majemuk yang sudah tumbuh sempurna dan jumlah cabang dihitung cabang yang muncul dari batang utama. Panen dilakukan Komponen hasil yang diamati pada saat panen terdiri atas jumlah umbi (butir), bobot umbi (kg); produktivitas (ton ha ${ }^{-1}$ ) serta persentase jumlah umbi (\%) berdasarkan standar bobot umbi Direktorat Perbenihan Hortikultura (2015), dengan pengelompokkan (a) Large (L)/besar: >90-120 g; (b) Medium (M)/sedang: 40-90 g; (c) Small (S)/kecil: <40 g.

Data dianalisis menggunakan analisis sidik ragam (uji F) pada taraf $\alpha=5 \%$. Apabila terdapat pengaruh interaksi antara sumber benih dan varietas yang nyata pada hasil uji $\mathrm{F}$, dilakukan uji lanjut menggunakan uji DMRT (Duncan's Multiple Range Test). Seluruh proses analisis data menggunakan perangkat lunak Microsoft ${ }^{\circledR}$ Office Excel 2016 dan Statistical Tool for Agricultural Research (STAR) versi 2.0.1.

\section{HASIL DAN PEMBAHASAN}

\section{Analisis Sidik Ragam}

Hasil analisis ragam pada setiap peubah menunjukkan bahwa terdapat pengaruh sangat 
nyata dari varietas pada peubah tinggi tanaman 2, 4, 6, dan 10 MST, jumlah daun 2, 8, dan 10 MST serta jumlah cabang 6-10 MST. Perlakuan sumber benih memberikan pengaruh sangat nyata pada peubah tinggi tanaman 2-10 MST, jumlah daun 2-10 MST, jumlah cabang 2-10 MST, \% umbi kelas S, \% umbi kelas M, \% umbi kelas L, dan bobot umbi. Interaksi antara varietas dan sumber benih berpengaruh sangat nyata pada peubah tinggi tanaman 2-6 MST, jumlah daun 2-10 MST, serta jumlah cabang 4$6 \mathrm{MST}, \%$ umbi kelas S, dan \% umbi kelas M (Tabel 1).

\section{Tinggi Tanaman}

Analisis sidik ragam pada peubah tinggi tanaman menunjukkan perbedaan yang nyata sehingga analisis data dilanjutkan dengan uji lanjut Duncan pada taraf 0.05 (Tabel 2). Tinggi tanaman kentang yang ditanam menggunakan setek lebih tinggi dibandingkan umbi pada awal masa pertumbuhan (2-4 MST). Namun, di akhir masa pertumbuhan tinggi tanaman tidak berbeda nyata antara kedua varietas dan sumber benih (8-10 MST). Pertambahan tinggi tanaman kentang yang ditanam dengan setek relatif lebih lambat dibandingkan dengan kentang yang ditanam menggunakan umbi. Umbi sebagai bahan perbanyakan kentang memiliki cadangan asimilat yang dapat digunakan untuk menunjang pertumbuhan, sedangkan setek yang dipindah tanam ke lapangan akan mengalami cekaman dan membutuhkan waktu untuk dapat beradaptasi. Lommen (2015) menyatakan bahwa asimilat tanaman kentang dari setek yang ditanam di lapangan akan banyak ditranslokasikan untuk perkembangan umbi bukan untuk perkembangan tanaman. Setek kentang berumur 28 hari yang dipindah tanam ke lapangan mentranslokasikan 85\% asimilat untuk pembentukan umbi pada awal pertumbuhan.

Tabel 1. Rekapitulasi sidik ragam berbagai peubah pengamatan

\begin{tabular}{|c|c|c|c|c|}
\hline Peubah & $\mathrm{V}$ & $\mathrm{S}$ & $\mathrm{V} * \mathrm{~S}$ & $\mathrm{KK}(\%)$ \\
\hline \multicolumn{5}{|l|}{ Tinggi tanaman } \\
\hline $2 \mathrm{MST}$ & ** & $* *$ & $* *$ & 12.32 \\
\hline $4 \mathrm{MST}$ & $* *$ & $* *$ & $* *$ & 11.50 \\
\hline $6 \mathrm{MST}$ & $* *$ & $* *$ & $* *$ & 8.85 \\
\hline $8 \mathrm{MST}$ & tn & $* *$ & tn & 9.88 \\
\hline $10 \mathrm{MST}$ & ** & $* *$ & tn & 9.03 \\
\hline \multicolumn{5}{|l|}{ Jumlah daun } \\
\hline $2 \mathrm{MST}$ & $* *$ & $* *$ & $* *$ & 15.29 \\
\hline $4 \mathrm{MST}$ & tn & $* *$ & $* *$ & 17.25 \\
\hline $6 \mathrm{MST}$ & tn & $* *$ & $* *$ & 15.64 \\
\hline $8 \mathrm{MST}$ & $* *$ & $* *$ & $* *$ & 13.56 \\
\hline $10 \mathrm{MST}$ & $* *$ & $* *$ & $* *$ & 10.91 \\
\hline \multicolumn{5}{|l|}{ Jumlah cabang } \\
\hline $2 \mathrm{MST}$ & tn & $* *$ & tn & 24.90 \\
\hline $4 \mathrm{MST}$ & $*$ & $* *$ & $* *$ & 25.01 \\
\hline $6 \mathrm{MST}$ & ** & $* *$ & $* *$ & 26.89 \\
\hline $8 \mathrm{MST}$ & ** & $* *$ & $*$ & 16.98 \\
\hline $10 \mathrm{MST}$ & $* *$ & $* *$ & $*$ & 15.22 \\
\hline Jumlah Umbi & tn & tn & tn & 20.30 \\
\hline$\%$ umbi kelas $\mathrm{S}$ & tn & $* *$ & $* *$ & 8.91 \\
\hline$\%$ umbi kelas $\mathrm{M}$ & tn & $* *$ & $* *$ & 25.68 \\
\hline$\%$ umbi kelas L & tn & $* *$ & tn & 59.34 \\
\hline Bobot umbi & tn & $* *$ & $*$ & 29.88 \\
\hline
\end{tabular}

Keterangan: V: varietas, S: sumber benih, V*S: varietas*sumber benih, KK: koefisien keragaman, MST: minggu setelah tanam, *: berpengaruh nyata pada taraf $\alpha=5 \%, * *$ : berpengaruh nyata pada taraf $\alpha=1 \%$, tn: tidak berpengaruh nyata. 
Tabel 2. Pengaruh interaksi antara varietas dan sumber benih pada peubah tinggi tanaman $(\mathrm{cm})$

\begin{tabular}{clrc}
\hline \multirow{2}{*}{ MST } & \multicolumn{2}{c}{ Perlakuan } & \multicolumn{3}{c}{ Umbi } & Setek \\
\cline { 2 - 4 } & Varietas & $4.84 \mathrm{aB}$ & $13.84 \mathrm{aA}$ \\
2 & RGH01 & $0.00 \mathrm{bB}$ & $14.50 \mathrm{aA}$ \\
& Medians & $10.59 \mathrm{aB}$ & $17.28 \mathrm{aA}$ \\
4 & RGH01 & $5.54 \mathrm{bB}$ & $17.96 \mathrm{aA}$ \\
& Medians & $19.73 \mathrm{aA}$ & $18.93 \mathrm{aA}$ \\
6 & RGH01 & $14.05 \mathrm{bB}$ & $20.15 \mathrm{aA}$ \\
& Medians & 27.02 & 22.13 \\
\multirow{2}{*}{8} & RGH01 & 27.38 & 23.38 \\
& Medians & 30.86 & 26.04 \\
& RGH01 & 38.82 & 29.67 \\
\hline
\end{tabular}

Keterangan: MST = minggu setelah tanam. Angka yang diikuti huruf kapital yang sama pada baris yang sama atau huruf kecil yang sama pada kolom yang sama menunjukkan nilai tidak berbeda nyata pada setiap minggu pengamatan dengan uji DMRT pada $\alpha=5 \%$.

\section{Jumlah Daun}

Interaksi antara penggunaan varietas dan sumber benih pada peubah jumlah daun terjadi selama masa pertumbuhan (Tabel 3). Pengaruh varietas menunjukkan bahwa jumlah daun terbanyak dihasilkan oleh varietas Medians pada kedua sumber benih. Pengaruh sumber benih menunjukkan kedua varietas yang ditanam menggunakan setek menghasilkan jumlah daun yang lebih banyak dibandingkan tanaman kentang yang ditanam dengan sumber benih umbi. Tanaman kentang yang ditanam dengan sumber benih setek pada penelitian McCown dan Wattimena (1987) menghasilkan jumlah nodus yang lebih banyak dibandingkan sumber benih lainnya. Jumlah nodus merupakan indikasi dari banyaknya jumlah daun.

Luas daun dan Index Luas Daun (ILD) berpengaruh terhadap penutupan permukaan tanah dan penerimaan radiasi matahari oleh tanaman kentang yang ditanam menggunakan benih sumber setek (Haverkort et al., 1991; Tadesse et al., 2001; Tekalign dan Hammes, 2005; Särekanno et al., 2010c; Lommen; 2015). Pengaruh jumlah daun terhadap penutupan permukaan tanah dan penerimaan radiasi matahari belum banyak dilaporkan. Jumlah daun yang lebih banyak seharusnya berkorelasi dengan luas daun dan ILD sehingga penutupan permukaan tanah dan penerimaan radiasi lebih tinggi.

Tabel 3. Pengaruh interaksi antara varietas dan sumber benih pada peubah jumlah daun

\begin{tabular}{clrc}
\hline \multirow{2}{*}{ MST } & \multicolumn{2}{c}{ Perlakuan } & \multicolumn{2}{c}{ Sumber Benih } \\
\cline { 2 - 4 } & \multicolumn{1}{c}{ Varietas } & Umbi & \multicolumn{1}{c}{ Setek } \\
\hline 2 & RGH01 & $4.6 \mathrm{aB}$ & $\mathrm{bA}$ \\
& Medians & $0.0 \mathrm{bB}$ & $6.9 \mathrm{aA}$ \\
\multirow{2}{*}{4} & RGH01 & $8.9 \mathrm{aA}$ & $9.2 \mathrm{bA}$ \\
& Medians & $6.5 \mathrm{bB}$ & $12.1 \mathrm{aA}$ \\
\multirow{2}{*}{6} & RGH01 & $15.6 \mathrm{aA}$ & $16.8 \mathrm{bA}$ \\
& Medians & $12.5 \mathrm{aB}$ & $23.9 \mathrm{aA}$ \\
\multirow{2}{*}{8} & RGH01 & $20.9 \mathrm{aA}$ & $22.5 \mathrm{bA}$ \\
& Medians & $21.9 \mathrm{aB}$ & $36.0 \mathrm{aA}$ \\
& RGH01 & $28.1 \mathrm{bA}$ & $31.2 \mathrm{bA}$ \\
& Medians & $37.0 \mathrm{aB}$ & $51.2 \mathrm{aA}$
\end{tabular}

Keterangan: MST = minggu setelah tanam. Angka yang diikuti huruf kapital yang sama pada baris yang sama atau huruf kecil yang sama pada kolom yang sama menunjukkan nilai tidak berbeda nyata pada setiap minggu pengamatan dengan uji DMRT pada $\alpha=5 \%$. 
Namun, menurut Tadesse et al., 2001 inisiasi umbi tanaman kentang dari sumber benih setek terjadi pada lebih awal sedangkan penerimaan radiasi masih rendah atau asismilat yang terlalu banyak dialokasikan pada umbi sehingga mempengaruhi pertumbuhan dan perkembangan daun. Hal serupa juga dilaporkan oleh Tekalign dan Hammes (2005) dimana keterbatasan asimilat mengakibatkan terjadi persaingan antar organ untuk memperoleh asimilat. Asimilat akan lebih banyak ditranslokasikan ke umbi atau terjadi pengurangan alokasi asimilat ke organ lain. Berikutnya, Lommen (2015) menyatakan alokasi asimilat yang tinggi ke umbi pada tanaman kentang yang ditanam dengan setek berdampak pada rendahnya tingkat perkembangan daun dan juga ukuran daun sehingga total penerimaan radiasi (accumulated intercepted radiation) menurun akibat rendahnya penutupan permukaan tanah.

\section{Jumlah Cabang}

Pengaruh varietas (Tabel 4) pada 4 hingga 8 MST menunjukkan tidak terdapat perbedaan antara jumlah cabang pada cv. RGH01 dan Medians yang ditanam dengan sumber benih umbi. Varietas Medians yang ditanam dengan umbi maupun setek memiliki jumlah cabang lebih banyak dibandingkan cv. RGH01 pada 10 MST. Pengaruh sumber benih menunjukkan bahwa jumlah cabang tanaman kentang yang ditanam dengan sumber benih setek lebih banyak dibandingkan dengan penggunaan umbi pada kedua varietas. Semakin banyak cabang maka kemampuan tanaman untuk menghasilkan daun yang lebih banyak juga tinggi. Menurut Wattimena et al. (1983), salah satu kelemahan tanaman kentang yang memiliki cabang yang lebih sedikit adalah meningkatnya kerentanan terhadap kehilangan akibat serangan hama penyakit dan sebaliknya.

\section{Pengaruh Interaksi terhadap Komponen Hasil}

Interaksi antara kedua faktor mempengaruhi persentase jumlah umbi kelas $S$, persentase jumlah umbi kelas $M$ dan produktivitas (Tabel 5). Pengaruh sumber benih menunjukkan bahwa tanaman kentang dari setek menghasilkan persentase jumlah umbi kelas S lebih besar (82.0-94.1\%) dan berbeda nyata terhadap tanaman kentang dari umbi pada kedua varietas. Sebaliknya, persentase jumlah umbi kelas $\mathrm{M}$ dan $\mathrm{L}$ yang dihasilkan oleh tanaman kentang dari umbi lebih besar terhadap tanaman kentang dari setek. Bobot umbi per hektar terbesar diperoleh dari tanaman kentang yang ditanam dengan umbi, hal ini dikarenakan tanaman yang ditanam dengan umbi memiliki persentase jumlah umbi kelas $\mathrm{M}$ dan $\mathrm{L}$ lebih besar.

Tabel 4. Pengaruh interaksi antara varietas dan sumber benih pada peubah jumlah cabang

\begin{tabular}{clcc}
\hline \multirow{2}{*}{ MST } & \multicolumn{1}{c}{ Perlakuan } & \multicolumn{3}{c}{ Sumber Benih } \\
\cline { 2 - 4 } & \multicolumn{1}{c}{ Varietas } & 0.0 & Setek \\
\hline 2 & RGH01 & 0.0 & 0.2 \\
& Medians & $0.2 \mathrm{aB}$ & 0.2 \\
\multirow{2}{*}{4} & RGH01 & $0.1 \mathrm{aB}$ & $0.7 \mathrm{bA}$ \\
& Medians & $1.1 \mathrm{aB}$ & $1.1 \mathrm{aA}$ \\
\multirow{2}{*}{6} & RGH01 & $1.1 \mathrm{aB}$ & $2.0 \mathrm{bA}$ \\
& Medians & $1.6 \mathrm{aB}$ & $3.6 \mathrm{aA}$ \\
\multirow{2}{*}{10} & RGH01 & $2.2 \mathrm{aB}$ & $2.7 \mathrm{bA}$ \\
& Medians & $2.0 \mathrm{bB}$ & $3.4 \mathrm{aA}$ \\
& RGH01 & $2.9 \mathrm{aB}$ & $5.0 \mathrm{aA}$
\end{tabular}

Keterangan: MST= minggu setelah tanam. Angka yang diikuti huruf kapital yang sama pada baris yang sama atau huruf kecil yang sama pada kolom yang sama menunjukkan nilai tidak berbeda nyata pada setiap minggu pengamatan dengan uji DMRT pada $\alpha=5 \%$. 
Tabel 5. Pengaruh interaksi antara varietas dan sumber benih pada peubah komponen hasil

\begin{tabular}{llcc}
\hline \multirow{2}{*}{ Komponen Hasil } & \multicolumn{2}{c}{ Perlakuan } & \multicolumn{2}{c}{ Sumber Benih } \\
\cline { 2 - 4 } & \multicolumn{1}{c}{ Varietas } & Umbi & Setek \\
\hline Jumlah umbi tanaman & -1 & 5.2 & 5.7 \\
& Redians & 5.7 & 5.9 \\
\% Kelas S & RGH01 & $55.1 \mathrm{bB}$ & $94.1 \mathrm{aA}$ \\
& Medians & $70.4 \mathrm{aB}$ & $82.0 \mathrm{bA}$ \\
\% Kelas M & RGH01 & $33.3 \mathrm{aA}$ & $4.1 \mathrm{bB}$ \\
\% Kelas L & Medians & $21.8 \mathrm{bA}$ & $13.9 \mathrm{aB}$ \\
& RGH01 & 11.6 & 1.8 \\
Bobot umbi $\left(\right.$ g tanaman $\left.^{-1}\right)$ & Medians & 8.0 & 4.1 \\
& RGH01 & $217.1 \mathrm{aA}$ & $73.2 \mathrm{bB}$ \\
& Medians & $172.7 \mathrm{aA}$ & $135.3 \mathrm{aA}$ \\
\hline
\end{tabular}

Keterangan: Angka yang diikuti huruf kapital yang sama pada baris yang sama atau huruf kecil yang sama pada kolom yang sama menunjukkan nilai tidak berbeda nyata pada setiap minggu pengamatan dengan uji DMRT pada $\alpha=5 \%$.

Jumlah umbi per tanaman tidak berbeda nyata pada kedua varietas dan sumber benih yaitu berkisar antara 5.2-5.9 knol. Hal ini sejalan dengan Wattimena et al. (1983) dan Lecrec dan Donnelly (1990), bobot basah umbi dari tanaman kentang yang ditanam dengan umbi dan setek tidak berbeda nyata, namun jumlah umbi dari tanaman kentang setek lebih banyak dan berukuran lebih kecil. Penelitian yang dilakukan oleh Levy (1988) menunjukkan bahwa tanaman setek yang ditanam di lapangan mampu menghasilkan jumlah umbi antara 4.3 hingga 13.1 umbi.

Penggunaan setek sebagai sumber benih untuk menghasilkan umbi G2 kentang di lapang memperlihatkan hasil yang tidak berbeda nyata dengan jumlah umbi yang diperoleh dari sumber benih umbi. Produksi umbi G2 kentang menggunakan sumber benih setek relatif lebih cepat karena tidak melalui masa dormansi layaknya umbi sehingga dapat digunakan untuk mempercepat produksi dan distribusi umbi G2 kentang salah satunya untuk tujuan pengembangan varietas baru atau hasil introduksi. Disamping itu, persentase jumlah umbi kelas $\mathrm{S}$ yang dihasilkan lebih besar. Benih umbi kelas $S$ juga lebih mudah untuk disimpan dan diangkut. Umbi kelas S lebih disukai oleh petani namun kurang disukai oleh penangkar karena umbi G2 dijual berdasarkan bobot bukan satuan atau knol.

Teknik budi daya yang tepat untuk mendukung produksi benih G2 menggunakan setek sebagai sumber benih perlu dilakukan untuk mengoptimalkan pertumbuhan dan hasil. Penelitian selanjutnya dapat difokuskan untuk menghasilkan tanaman kentang yang memiliki keragaan baik serta jumlah umbi berukuran kecil (kelas) yang lebih banyak. Beberapa teknik budidaya yang dapat diterapkan antara lain pemilihan varietas (Tekalign dan Hammes, 2005; Wrobel, 2014), penggunaan umur setek yang optimal (Lommen, 2015.), kerapatan tanam dan jarak tanam (Sutapradja, 2008; Masarirambi et al., 2012; Al Mamun et al., 2016), penggunaan mulsa (Hamdani, 2009; Rogi et al., 2016), aplikasi pupuk hara mikro dan pupuk daun (Mausavi et al., 2007) serta penggunaan sungkup plastik pada awal penanaman.

\section{KESIMPULAN}

Jumlah umbi per tanaman tidak dipengaruhi oleh interaksi antara sumber benih dan varietas Kentang yang ditanam menggunakan sumber benih setek pada kedua varietas menghasilkan jumlah daun dan cabang lebih banyak. Persentase jumlah umbi kelas $S$ $(<40 \mathrm{~g})$ lebih banyak dihasilkan oleh tanaman kentang yang ditanam dengan setek pada kedua varietas. Produktivitas umbi yang lebih besar dihasilkan oleh tanaman kentang dengan sumber benih umbi pada kedua varietas.

\section{DAFTAR PUSTAKA}

Al-Mamun, M.A., A. Al-Mahmud, M. Zakaria, M.M. Hossain, M.T. Hossain. 2016. Effects of planting times and plant densities of top-shoot cuttings on multiplication of breeder seed potato. J. Agric. Nat. Resour. Sci. 50:26-31. 
Direktorat Perbenihan Hortikultura. 2014. Teknis Perbanyakan dan Sertifikasi Benih Kentang (Solanum tuberosum L.). Direktorat Perbenihan Hortikultura, Direktorat Jenderal Hortikultura, Kementerian Pertanian, Jakarta.

Direktorat Perbenihan Hortikultura. 2015. Standar Operasional Produksi Benih Kentang (Solanum tuberosum L.). Direktorat Perbenihan Hortikultura, Direktorat Jenderal Hortikultura, Kementerian Pertanian, Jakarta.

Duriat, A.S., O.S. Gunawan, N. Gunaeni. 2006. Penerapan Teknologi PHT Pada Tanaman Kentang. Balai Penelitian Tanaman Sayuran (Balitsa), Bandung.

Hamdani, J.S. 2009. Pengaruh jenis mulsa terhadap pertumbuhan dan hasil tiga varietas kentang (Solanum tuberosum L.) yang ditanam di dataran medium. J. Agron. Indonesia. 37(1): 14-20.

Haverkort, A.J., D. Uenk, H. Veroude, M. van de Waart. 1991. Relationships between ground cover, intercepted solar radiation, leaf area index and infrared reflectance of potato crops. Potato Res 34: 113-121.

Hossain, Md.S., M.M Hossain, M.M Haque, Md.M Haque, Md.D Sarkar. 2017. Varietal evalutation of potato microtuber and planlet in seed tuber production. Ann. Agric. Science. 2017: 1-5.

[Kementan] Kementerian Pertanian. 2006a. Deskripsi Kentang Varietas Granola Kembang.http://perundangan.pertanian. go.id/admin/file/SK-81-05.pdf $[18$ Desember 2017].

[Kementan] Kementerian Pertanian. 2006b. Peraturan Menteri Pertanian Nomor 40 Tahun 2006 tentang Pedoman Perbenihan Kentang. Kementerian Pertanian, Jakarta.

[Kementan] Kementerian Pertanian. 2017. Produktivitas kentang menurut provinsi, 2012-2016. http://www.pertanian.go.id/ Data5tahun. [18 Desember 2017].
Lecrec, Y., D.J Donnelly. 1990. Seasonal differences in the field performance of micropropagated potato under a short growing season in Quebec. Am. Potato J. 67(8): 507-516.

Levy, D. 1988. Propagation of potato by the transfer of transplants of in vitro profilerated shoot cutting into the field. Scientia Hortic. 36(3): 165-171.

Lommen, W.J.M. 2015. How age of transplants from in vitro derived potato plantlets affects crop growth and seed tuber yield after field transplanting. Potato Res. 58(4): 343-360.

Mahmud, A.A., M.A. Hoque, A.A. Mamun, M.M. Bazzaz, M.A. Hossain. 2012. Yield and profitability of potato as influenced by intra-row spacing and number of eye in cut tuber in northern region of Bangladesh. Ann. Bangladesh Agric. 14: 111-124.

Masarirambi, M.T., F.C. Mandisodza, A.B. Mashingaidze, E. Bhebhe. 2012. Influence of plant population and seed tuber size on growth and yield components of potato (Solanum tuberosum). Int. J. Agric. Biol. 14(4): 545-549.

Mausavi, S.R., M. Galvi, G. Ahmadvand. 2007. Effect of zinc and manganese foliar application on yield, quality and enrichment on Potato (Solanum tuberosum L.). Asian J. Plant Sci. 6(8): $1256-1260$

McCown, B.H., G.A. Wattimena. 1987. Field performance of micropropagated potato plants. p. 80-88. In Bajab YPD (ed.). Biotechnology in Agriculture and Forestry (book 3). Springer-Verlag. New York.

Rogi, J.E.X., H.S.G. Kembuan, J.A. Rombang. 2016. Laju tumbuh umbi tanaman kentang varietas Granola dan Superjohn di dataran medium dengan pemulsaan. J. Hort. Indonesia. 72(2): 83-90. 
Sayaka, B., J. Hestina. 2011. Kendala adopsi benih bersertifikat untuk usaha tani kentang. Forum Penelitian Agro Ekonomi. 29(1): 27-41.

Särekanno, M., J. Kadaja, K. Kotkas, V. Rosenberg, V. Vasar, A. Ojarand, V. Eremeev. 2010a. Potato seed from meristem plants using EVIKA multiplication methods. Acta Agric. Scand. B. 60(2): 101-109.

Särekanno, M., J. Kadaja, K. Kotkas, V. Rosenberg, V. Vasar, A. Ojarand, V. Eremeev. 2010b. Yield potential and tuber-size distribution using EVIKA multiplication methods. Acta Agric. Scand. B. 60(4): 297-306.

Särekanno, M., J. Kadaja, K. Kotkas, V. Rosenberg, V. Vasar, A. Ojarand, V. Eremeev. 2010c. Dependence of leaf area index on different multiplication methods of potato meristem plants grown under field conditions. Acta Agric. Scand. B. 60(1): 1-9.

Sutapradja, H. 2008. Pengaruh Jarak tanam dan ukuran umbi bibit terhadap pertumbuhan dan hasil kentang varietas granola untuk Bibit. J. Hort. 18(2): 155-159

Tadesse, M., W.J.M. Lommen, P.C. Struik. 2001. Development of micropropagated potato plants over three phases of growth as affected by temperature in different phases. NJAS-Wageningen Journal of Life Sciences. 49(1): 53-66.

Tekalign, T., P.S. Hammes. 2005. Growth and productivity of potato as influenced by cultivar and reproductive growth: II. Growth analysis, tuber yield and quality. J. Scienta. 105(1): 29-44.

Wattimena, G., B. McCown, G. Weis. 1983. Comparative field performance of potatoes from microculture. Am. Potato J. 60(1): 27-33.

Wattimena, G.A. 2006. Prospek plasma nutfah kentang dalam mendukung swasembada benih kentang di Indonesia. Penyusunan Action Plan dalam Rangka Swasembada Benih Kentang di Indonesia; Bandung, 19-21 April 2006

Wrobel, S. 2014. Assessment of Possibilities of Microtuber and in vitro Plantlet Seed Multiplication in Field Conditions. Part 1: PVY, PVM and PLRV Spreading. Am. J. Potato. Res.

Wrobel, S. 2015. Assessment of potato microtuber and in vitro planlet seed multiplication in field conditions growth, development and yield. Field Crops Res. 178: 26-33. 